\title{
Principais Aspectos da Resistência de Plantas Daninhas ao HeRBICIDA GLYPHOSATE ${ }^{1}$
}

\author{
Main Aspects on Weed Herbicide Resistance to Glyphosate \\ CHRISTOFFOLETI, P.J. ${ }^{2}$ e LÓPEZ-OVEJERO, R. ${ }^{3}$
}

\begin{abstract}
RESUMO - A seleção de biótipos de plantas daninhas resistentes a herbicidas na agricultura brasileira e mundial é um fenômeno já constatado e relatado para praticamente todos os herbicidas em uso na agricultura. A confirmação de um novo caso de resistência de planta daninha ao herbicida glyphosate através da espécie Lolium multiflorum (azevém), que corresponde ao primeiro caso relatado no Brasil para esse herbicida, preocupa o meio científico, produtivo e industrial, devido à importância desse herbicida para o manejo de plantas daninhas das diversas culturas. Assim, a discussão e compreensão do fenômeno da resistência são fundamentais para prevenir ou retardar a seleção de biótipos resistentes a herbicidas, sendo este o objetivo principal do presente artigo. São discutidos aspectos referentes a fatores ligados às plantas daninhas e aos sistemas de produção que interagem na seleção da resistência a herbicidas, o potencial de seleção de plantas daninhas resistentes ao glyphosate, o fluxo gênico e as formas de manejo e prevenção da resistência.
\end{abstract}

Palavras-chave: fluxo gênico, azevém, prevenção da resistência, manejo da resistência.

\begin{abstract}
The weed biotypes resistant to herbicides in the Brazilian and worldwide agriculture is a phenomenon reported for most of the herbicides in use in the agriculture. The confirmation of a new case of weed resistant to glyphosate by the species Lolium multiflorum that correspond to the first case in Brazil for this herbicide, leave the weed scientist, producers and industrial media concerned due to the importance of this herbicide for weed management in several crops. Therefore, the discussion and understanding of the resistance phenomenon is fundamental to delay or avoid the selection herbicide resistant weed biotypes, being this the main objective of this article. It is discussed aspects related to factors related to the weeds and cropping systems that interact in the selection of herbicide resistance, the potential of weed resistant to glyphosate, gene flow, and ways to delay or avoid resistance.
\end{abstract}

Key words: gene flow, lolium, resistance avoidance, resistance management.

\section{INTRODUÇÃO}

Uma das discussões atuais e inevitáveis na agricultura brasileira e mundial está relacionada com o potencial de seleção de biótipos de plantas daninhas resistentes ao herbicida glyphosate. Isso ocorre só pela utilização intensiva nas áreas de plantio direto e outras áreas onde é utilizado para o controle não-seletivo de plantas daninhas (por exemplo, café, fruticultura, florestas, etc.), mas também pelo potencial de aplicação nas culturas transgênicas tolerantes a esse herbicida. Recentemente, foi confirmado um novo caso de

\footnotetext{
Recebido para publicação em 10.9.2003 e na forma revisada em 12.12.2003.

2 Professor Associado do Departamento de Produção Vegetal, área de Biologia e Manejo de Plantas Daninhas, Escola Superior de Agricultura "Luiz de Queiroz", Universidade de São Paulo - USP/ESALQ/LPV, Caixa Postal 09, 13418-900 Piracicaba-SP, <pjchrist@esalq.usp.br>, Tel.: (19) 3429-4190; ${ }^{3}$ Doutorando do Programa de Pós-Graduação em Fitotecnia da ESALQ/USP, Caixa Postal 09, 13418-900 Piracicaba-SP, <rfloveje@esalq.usp.br>, Tel.: (19) 3429-4190.
} 
resistência de plantas daninhas ao herbicida glyphosate através da espécie Lolium multiflorum (azevém), que corresponde ao primeiro caso relatado no Brasil para esse herbicida. Por isso, é importante esclarecer alguns conceitos sobre o fenômeno da resistência a esse grupo de herbicidas (herbicidas inibidores da EPSPs, enzima responsável pela síntese dos aminoácidos aromáticos) e propor algumas alternativas de prevenção e manejo.

\section{RESISTÊNCIA DE PLANTAS DANINHAS A HERBICIDAS}

A ampla variabilidade genética é uma das principais características das plantas daninhas, que permite a adaptação e a sobrevivência dessas espécies em diversas condições ambientais e do agroecossistema. Assim, devido à utilização intensiva de herbicidas nas últimas décadas, algumas populações de plantas daninhas foram selecionadas em resposta ao distúrbio ambiental provocado pela pressão de seleção dos herbicidas, com a seleção de biótipos a eles resistentes. Essa seleção de biótipos resistentes tem ocorrido para todas as classes de herbicidas, embora alguns mecanismos de ação tenham selecionado biótipos resistentes com mais freqüência que outros. Os herbicidas inibidores da ALS (sulfoniluréias e imidazolinonas), por exemplo, têm centenas de relatos de seleção de biótipos resistentes no mundo; já o glyphosate e os herbicidas inibidores de PROTOX, apesar de utilizados intensivamente na agricultura, têm poucos relatos de casos na agricultura mundial (Christoffoleti \&
López-Ovejero, 2003).

A resistência de plantas daninhas a herbicidas é a capacidade natural e herdável de alguns biótipos, dentro de uma determinada população de plantas daninhas, de sobreviver e se reproduzir após a exposição à dose de um herbicida, que seria letal a uma população normal (suscetivel) da mesma espécie (Christoffoleti \& López-Ovejero, 2003). Biótipo é um grupo de indivíduos com carga genética semelhante, pouco diferenciado da maioria dos indivíduos da população (Kissmann, 1996). Os registros apontam atualmente a existência de 284 biótipos resistentes em 270.000 locais do mundo, distribuídos entre 170 espécies (101 dicotiledôneas e 69 monocotiledôneas), segundo o "Herbicide Resistance Action Committee - HRAC". No Brasil, existem 11 biótipos resistentes registrados (Tabela 1).

A variabilidade genética natural existente em qualquer população de plantas daninhas é a responsável pela fonte inicial de resistência em uma população suscetivel de plantas daninhas. Assim, todas as populações de plantas daninhas, independentemente da aplicação de qualquer produto, provavelmente contêm plantas individuais (biótipos) que são resistentes a herbicidas (Kissmann, 1996). Geralmente, as mutações gênicas, que ocorrem em uma população suscetível que ainda não foi submetida à pressão de seleção pelo herbicida, são resultantes de outros fatores de recombinação genética, não sendo, portanto, induzidas pelo agente de seleção, ou seja, o herbicida. Não existe, até o momento, nenhuma evidência de que os

Tabela 1 - Espécies de plantas daninhas resistentes a herbicidas registrados no HRAC de ocorrência no Brasil

\begin{tabular}{|c|c|}
\hline Espécie & Mecanismo de ação \\
\hline Bidens pilosa (picão-preto) & Inibidores de ALS \\
\hline Bidens subalternans (picão-preto) & Inibidores de ALS \\
\hline Brachiaria plantaginea (capim-marmelada) & Inibidores de ACCase \\
\hline Euphorbia heterophylla (amendoim-bravo) & Inibidores de ALS \\
\hline Sagittaria motevidensis (sagitária) & Inibidores de ALS \\
\hline Echinochloa crus-galli (capim-arroz) & Auxinas sintéticas \\
\hline Echinochloa crus-pavonis (capim-arroz) & Auxinas sintéticas \\
\hline Fimbristylis milacea (cominho) & Inibidores de ALS AL \\
\hline Cyperus difformis (junquinho) & Inibidores de ALS \\
\hline Digitaria ciliaris (capim-colchão) & Inibidores de ACCase \\
\hline Lolium multiflorum (azevém) & Inibidores da EPSPs \\
\hline
\end{tabular}


herbicidas tenham algum efeito mutagênico nas plantas capaz de induzir ou criar resistência (Christoffoleti et al., 1994).

A resistência de plantas daninhas a herbicidas é resultante do processo evolucionário. Os biótipos resistentes ocorrem naturalmente em baixa freqüência, e a pressão de seleção exercida pela aplicação repetitiva de um determinado herbicida ou de herbicidas diferentes, mas que apresentam o mesmo mecanismo de ação, aumenta a freqüência dos indivíduos resistentes na população (Christoffoleti \& López-Ovejero, 2003). O surgimento da resistência aos herbicidas é identificado, geralmente, quando 30\% das plantas se mostram resistentes (Maxwell \& Mortimer, 1994). Normalmente, a resistência se apresenta em manchas, aumentando a sua proporção com a aplicação repetitiva do herbicida, dominando finalmente a área.

\section{FATORES DA PLANTA DANINHA E DO SISTEMA DE PRODUÇÃO QUE INTERAGEM NA SELEÇÃO DE BIÓTIPOS DE PLANTAS DANINHAS RESISTENTES A HERBICIDAS}

As características bioecológicas das plantas daninhas que favorecem a seleção de biótipos de plantas daninhas resistentes em uma área são: ciclo de vida curto, elevada produção de sementes, baixa dormência da semente, várias gerações reprodutivas por ano, extrema suscetibilidade a um determinado herbicida e grande diversidade genética (Christoffoleti et al., 1994; Vidal \& Fleck, 1997; Vargas et al., 1999). Dessa forma, não é qualquer planta daninha que possui potencial de terem selecionados biótipos resistentes rapidamente a determinado herbicida, ou seja, algumas espécies de plantas daninhas apresentam biótipos selecionados com mais freqüência que outras espécies que raramente teriam seus biótipos resistentes selecionados.

Dentre as práticas culturais que podem levar à seleção de biótipos resistentes de plantas daninhas, destacam-se: manejo de plantas daninhas através da utilização exclusiva de herbicidas; aplicação repetitiva do mesmo herbicida ou de herbicidas com o mesmo mecanismo de ação durante diversos anos agrícolas; sistemas de produção que não praticam com freqüência a rotação de culturas (monocultura) e herbicidas; pequena utilização de controle mecânico de plantas daninhas ou não-eliminação dos escapes de controle do herbicida; e não-utilização de seqüência de herbicidas para controle de plantas daninhas em uma cultura (Christoffoleti et al., 1994).

O azevém é uma gramínea anual, rústica, cespitosa, agressiva, de folhas finas e tenras. A espécie é adaptada a temperaturas mais baixas em climas mesotérmicos (não resiste ao calor de verão de climas tropicais), nos quais se desenvolve somente durante o inverno e a primavera. As plantas florescem e frutificam em abundância (Pupo, 1979). É uma espécie adaptada à região Sul do Brasil, que pode ser semeada como uma cultura agrícola com finalidade principal de uso forrageiro ou de formação de cobertura morta ou apresentar ressemeadura natural (espontânea). Dessa forma, é comum nas áreas agrícolas a ocorrência de plantas de azevém em diferentes estádios de crescimento, resultando em dificuldades de controle.

O azevém é uma espécie utilizada com vários propósitos, como, por exemplo, no sistema de plantio direto como cobertura de inverno, como cobertura viva ou morta em pomares e como forrageira. No sistema de plantio direto ou pomares, a dessecação, ou controle, dessa espécie é realizada normalmente com a aplicação de herbicidas não-seletivos, em diferentes estádios fenológicos, sendo o glyphosate o herbicida mais utilizado para esse fim. Assim, pelas características bioecológicas da planta daninha (variabilidade genética, alogamia, elevada produção de sementes, etc.) e pelas estratégias de manejo atualmente empregadas, a seleção de biótipos resistentes desta planta daninha ao glyphosate é possivel, conforme já têm sido observados casos em quatro países no mundo (Austrália, Chile, Estados Unidos e Brasil). É importante ressaltar que, embora a planta daninha azevém seja uma infestante da região Sul do Brasil, a época principal de maior incidência é o outono-inverno, não se constituindo, assim, em grande problema de infestação nas culturas de verão, como soja, milho, etc.

\section{GLYPHOSATE E A RESISTÊnCIA DE PLANTAS DANINHAS}

O glyphosate é um herbicida não-seletivo, de ação sistêmica, usado no controle de plantas 
daninhas anuais e perenes. O herbicida é utilizado nas culturas para manejo da vegetação antes do plantio da cultura, principalmente nas áreas de plantio direto e no manejo de plantas daninhas na linha de culturas perenes, como em pomares de frutíferas. O herbicida glyphosate é derivado de aminoácidos e tem como mecanismo de ação a inibição da enolpiruvil-shikimato-fosfato sintetase (EPSPs), enzima responsável por uma das etapas de síntese dos aminoácidos aromáticos triptofano, fenilalanina e tirosina (Kruse et al., 2000).

O herbicida glyphosate tem sido usado intensivamente na agricultura há mais de 25 anos; até o momento, um número muito limitado de populações de plantas daninhas sofreu pressão de seleção suficiente para seleção de biótipos resistentes. O primeiro caso de resistência de plantas daninhas ao glyphosate foi registrado em 1996. Até recentemente foram registradas ocorrências de biótipos resistentes em seis países, sendo eles de Lolium rigidum, Eleusine indica, Conyza canadensis, Lolium multiflorum, Conyza bonariensis e Plantago lanceolata (Weed Science, 2003).

Embora não seja possível afirmar que a seleção de populações de plantas daninhas resistentes ao herbicida glyphosate não ocorrerá, é notável que, embora seja o herbicida de maior volume de vendas no mundo - com intenso uso já por quase três décadas, sendo em muitos sistemas de produção aplicado inclusive de forma repetitiva -, tem selecionado apenas algumas populações de plantas daninhas resistentes (Tabela 2). Portanto, é evidente que este herbicida apresenta potencial reduzido de seleção de biótipos resistentes de plantas daninhas. Outros herbicidas, pertencentes às mais diversas classes químicas e mecanismos de ação, têm centenas de relatos de seleção de populações resistentes, especialmente os herbicidas do grupo químico das triazinas, dos inibidores da acetolactato sintase (ALS) e da acetil coenzima A carboxilase (ACCase).

O número reduzido de relatos sobre a seleção de populações de plantas daninhas resistentes ao herbicida glyphosate pode ser fundamentado nas características bioquímica, química e biológica desse herbicida nas plantas e no solo. Algumas das seguintes características podem explicar a baixa probabilidade de desenvolvimento de biótipos resistentes a esse herbicida na agricultura (Bradshaw et al., 1997; Bracamonte et al., 2001):

i) Não apresenta residual no solo porque é rapidamente adsorvido pelas partículas coloidais, sofrendo rápida inativação, além de prontamente degradado por microrganismos, o que leva a uma menor pressão de seleção, quando comparado com herbicidas residuais.

ii) Múltiplos mecanismos fisiológicos que interagem na definição da sensibilidade ao glyphosate.

iii) Baixa adaptabilidade ecológica dos indivíduos sobreviventes. Entende-se por adaptabilidade ecológica a capacidade que um biótipo possui - dentro de uma população de plantas daninhas - de manter ou aumentar sua proporção ao longo do tempo (Christoffoleti et al., 1994). Qualquer alteração potencial na EPSPs das plantas daninhas que confere resistência ao glyphosate tem um impacto

Tabela 2 - Ano de introdução de alguns herbicidas e ano da constatação do primeiro caso de resistência de um biótipo de uma espécie antes bem controlada

\begin{tabular}{|l|c|c|c|c|}
\hline \multicolumn{1}{|c|}{ Herbicida } & Introdução & Resistência & Anos para aparecimento & Países \\
\hline 2,4-D & 1948 & 1957 & 9 & EUA e Canadá \\
\hline Triazinas & 1959 & 1970 & 11 & EUA \\
\hline Paraquat & 1966 & 1980 & 14 & Japão \\
\hline Inibidores da EPSPs & 1974 & 1996 & 22 & Austrália \\
\hline Inibidores da ACCase & 1977 & 1982 & 5 & Austrália \\
\hline Inibidores da ALS & 1982 & 1984 & 2 & Austrália \\
\hline
\end{tabular}

Fonte: Kissmann (1996). 
negativo na habilidade competitiva da planta daninha para sobreviver. Situação similar ocorre para o grupo das triazinas; no entanto, para os herbicidas pertencentes ao grupo dos inibidores de ALS (imidazolinonas e sulfoniluréias), as diminuições da adaptabilidade das plantas daninhas resistentes não têm sido observadas (Christoffoleti, 2002).

iv) Baixa freqüência inicial de plantas resistentes. A freqüência inicial do genoma resistente a herbicidas determina a rapidez no desenvolvimento da resistência. Assim, quanto maior a freqüência inicial do biótipo resistente, maior a probabilidade de aumentar a proporção de indivíduos resistentes, na população, em menor periodo de tempo com aplicações sucessivas do herbicida selecionador. Para alguns grupos de herbicidas essa freqüência é conhecida, como, por exemplo, as triazinas $\left(10^{-10} \mathrm{e}\right.$ $10^{-20}$ plantas) e os inibidores da ALS e de ACCase (10 $10^{-6}$ plantas) (Vidal \& Fleck, 1997).

v) Ausência de outros herbicidas do mesmo mecanismo de ação.

vi) Ausência na natureza de espécies de plantas que degradam quantidades significativas de glyphosate.

Ainda, segundo Pratley (2000), a demora no surgimento de biótipos resistentes ao glyphosate por tantos anos em áreas onde são cultivadas culturas anuais estaria relacionada com a modalidade de uso. Após a aplicação do herbicida em pré-semeadura, qualquer falha de controle poderia estar mascarada se posteriormente fosse realizado o preparo do solo ou se as plantas sobreviventes forem controladas com herbicidas pós-emergentes seletivos, como os graminicidas. Em razão disso, um biótipo resistente precisa passar por essas fases para acrescentar sementes no banco de sementes.

É importante mencionar, que nos ensaios de campo e casa de vegetação realizados com o azevém resistente no Brasil, a resistência ao glyphosate não foi absoluta, como para os inibidores da ALS, ou seja, no caso do glyphosate, quando se aumenta a dose pode-se controlar a planta daninha. Esse fato não ocorre, por exemplo, para o picão-preto (Bidens pilosa) resistente aos inibidores da ALS, em que o biótipo resistente não é controlado pelo herbicida, independentemente da dose utilizada.
Diversas pesquisas têm sido conduzidas nos últimos anos com o objetivo de elucidar o mecanismo de resistência de plantas daninhas ao glyphosate; o assunto ainda não está completamente esclarecido. Dentre os possiveis mecanismos de resistência, destacam-se a absorção, a translocação, a metabolização e as alterações da enzima alvo do glyphosate.

Estudos com L. rigidum feitos por Feng et al. (1999) e Pratley et al. (1999) determinaram o mecanismo potencial de resistência dessa planta daninha ao glyphosate. A absorção, a translocação e o metabolismo de Glyphosate- $\mathrm{C}^{14}$ foram comparados entre biótipo resistente (R) e suscetivel (S). Os resultados desses estudos demonstraram um padrão de absorção, translocação e metabolismo do glyphosate similar entre os biótipos R e S. Esses resultados sugerem que esses mecanismos não estariam relacionados com a resistência dessa espécie ao glyphosate porém isso pode ocorrer com outras espécies, como, por exemplo, E. indica, na Malásia; segundo Lee \& Ngim (2000) e Tran et al. (1999), esta planta daninha apresenta resistência múltipla com os herbicidas inibidores da ACCase, sugerindo como mecanismo de resistência o metabolismo diferencial entre os biótipos $\mathrm{R}$ e $\mathrm{S}$.

Um dos principais trabalhos visando a elucidação do mecanismo de resistência de L. rigidum ao glyphosate foi desenvolvido por Baerson et al. (2002). Inicialmente os autores observaram que numa população dessa espécie existiam plantas com diferentes niveis de tolerância ao herbicida, classificando-as como planta suscetivel (S); como intermediária (I) eles classificaram as plantas que toleram as doses de até $0,5 \mathrm{~kg}$ de e.a. ha ${ }^{-1}$; como resistente (R), aquelas que toleram as doses de até $1,5 \mathrm{~kg}$ e.a. ha-1; e altamente resistente (A), as que toleram as doses de até $3,0 \mathrm{~kg}$ e.a. ha-1. Esse fato também foi observado no Brasil, onde as plantas resistentes de azevém apresentaram diferentes graus de tolerância ao glyphosate (plantas que são controladas com 2,0 L ha ${ }^{-1} \mathrm{e}$ outras necessitam de 4,0 $\mathrm{L} \mathrm{ha}^{-1}$ e outras até $6,0 \mathrm{~L} \mathrm{ha}^{-1}$ ). Ainda no trabalho de Baerson et al. (2002), foi feito o isolamento da EPSPs e teste in vitro de sua atividade na presença de 1,6 $\mu \mathrm{M}$ de glyphosate em todas as linhagens. Conforme pode ser observado pelos resultados da Tabela 3, a atividade da EPSPs das plantas

Planta Daninha, Viçosa-MG, v.21, n.3, p.507-515, 2003 
resistentes é similar à das plantas suscetíveis, descartando-se a hipótese de alteração da EPSPs no sítio de ação do glyphosate.

Baerson et al. (2002) quantificaram o nível de EPSPs nas diferentes linhagens no momento da aplicação ( $\mathrm{t}=0$ hora + glyphosate) e 48 horas após aplicação do glyphosate $(\mathrm{t}=48$ horas + glyphosate); os resultados podem ser observados na Figura 1.

Tabela 3 - Inibição da EPSPs através de testes in vitro

\begin{tabular}{|l|c|c|}
\hline \multirow{2}{*}{ Linhagem } & \multicolumn{2}{|c|}{$\begin{array}{c}\text { \% de inibição por } 1,6 \mu \mathrm{M} \\
\text { glyphosate }\end{array}$} \\
\cline { 2 - 3 } & $\begin{array}{c}0 \mathrm{~h} \text { após } \\
\text { aplicação }\end{array}$ & $\begin{array}{c}48 \mathrm{~h} \text { após } \\
\text { aplicação }\end{array}$ \\
\hline Suscetível (S) & $42,9 \pm 4,0$ & $38,3 \pm 7,4$ \\
\hline Intermediária (I) & $44,3 \pm 3,0$ & $42,4 \pm 8,8$ \\
\hline Resistente (R) & $42,2 \pm 2,5$ & $43,6 \pm 2,9$ \\
\hline Altamente resistente (A) & $36,6 \pm 6,5$ & $44,5 \pm 2,8$ \\
\hline
\end{tabular}

Fonte: Baerson et al.(2002).

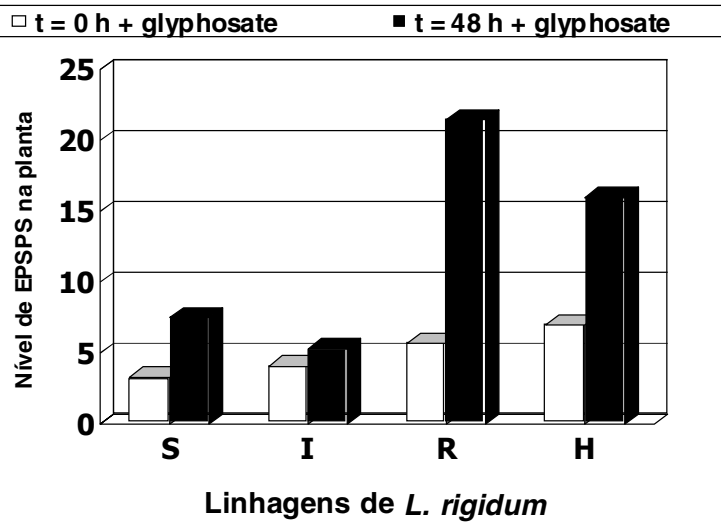

Fonte: Baerson et al.(2002).

Figura 1 - Quantificação do nível da EPSPs nas diferentes linhagens de L. rigidum.

Os resultados da Figura 1 sugerem uma superprodução da EPSPs induzida pela aplicação do glyphosate como sendo o mecanismo potencial de resistência do L. rigidum. As linhagens $\mathrm{R} \mathrm{e} \mathrm{H}$ apresentaram expressivo aumento do nível de EPSPs na planta 48 horas após aplicação do glyphosate, confirmando a hipótese de que a presença desse herbicida induziu uma rápida produção da enzima pelas plantas $\mathrm{R}$ e $\mathrm{H}$, fato que não aconteceu nas plantas $\mathrm{S}$ e I. Os autores observaram também que o nível de RNA mensageiro responsável pela transcrição da EPSPs era maior nas plantas $\mathrm{R}$ 48 horas após aplicação do glyphosate. No entanto, os estudos relativos aos níveis de DNA responsáveis pela tradução do RNA mensageiro não apresentaram diferença entre as linhagens de L. rigidum.

\section{O FLUXO GÊNICO}

Outra consideração importante na resistência de plantas daninhas a herbicidas é o fluxo gênico. É a transferência de material genético de uma espécie (daninha ou cultivada) para outras plantas (da mesma espécie ou de espécies diferentes), que podem apresentar novos caracteres na sua progênie (Arias \& Rieseberg, 1994). O fluxo gênico (via pólen) é um processo que depende de vários fatores, como: sincronismo floral, elevada compatibilidade, abundância de vetores e métodos de difusão de pólen, distância de movimentação do pólen e condições ambientais apropriadas para polinização cruzada (Carpenter et al., 2002).

O fluxo gênico e a pressão de seleção dentro das populações (intra-específica) são os modos mais importantes na evolução da resistência, porque favorecem o aumento da freqüência de plantas daninhas resistentes em uma população. Biótipos resistentes que se reproduzem, preferencialmente, pela autofecundação (autogamia) apresentam velocidade de dispersão muito pequena, quando comparados a biótipos que apresentam fecundação cruzada (alogamia), em razão da dificuldade do fluxo de genes entre plantas vizinhas. Também, em espécies alógamas existe maior probabilidade de ocorrência de múltiplos mecanismos de resistência, pois a polinização cruzada permite maior recombinação gênica (Christoffoleti \& López-Ovejero, 2003). Já a transferência de genes interespecífica através do fluxo gênico é muito rara.

Segundo Carpenter et al. (2002), o risco de fluxo gênico da característica de resistência da soja transgênica resistente ao glyphosate para outras espécies de plantas é insignificante para as regiões de cultivo da América do Norte e América Latina. Essa impossibilidade de fluxo gênico, no caso da soja, deve-se ao fato de a 
soja ser uma cultura originária do continente asiático - autógama com baixo potencial de cruzamento natural $(=1 \%)$ e complexo processo de cruzamento - e não ter a preferência do agente de polinização (abelhas). Ainda não há relatos científicos de transferência de genes de resistência a glyphosate de culturas para plantas daninhas. Assim, é de se considerar que não existe risco de transferência de genes de resistência ao glyphosate de uma planta de azevém para outra espécie de planta daninha ou cultivada.

\section{CONFIRMAÇÃO DA RESISTÊNCIA}

A suposição inicial de resistência geralmente está baseada no controle insatisfatório de plantas daninhas a uma aplicação de herbicida. Uma falha de controle pelo herbicida não significa, na maioria dos casos, que o agricultor está com problemas de plantas daninhas resistentes. Dessa forma, a resistência pode ser considerada a causa possivel quando todos os outros fatores de ineficácia de um herbicida tiverem sido analisados. Por isso, é importante realizar uma observação cuidadosa de alguns fatores a campo, para que qualquer redução na eficiência do herbicida possa ser detectada, como (CBRPH, 2000): i) fatores de aplicação do herbicida: dose ou momento inadequado de aplicação, falhas de pulverização; ii) condições do solo: umidade, preparo, adsorção, práticas agrícolas; iii) condições climáticas: regime de chuvas e temperatura; iv) fatores das plantas daninhas: tipo de planta daninha, estádio de desenvolvimento, novo surto germinativo, infestação muito alta; v) plantas vivas ao lado de plantas mortas podem indicar um desenvolvimento de resistência; e vi) nível de controle de outras espécies infestantes, entre outros.

\section{MANEJ O E PREVE NÇÃO DA RESISTÊ NCIA}

Guando ocorrem plantas daninhas resistentes aos herbicidas em uma área com densidade suficiente para limitar a produção das culturas agrícolas, há necessidade de mudanças nas práticas de manejo utilizadas. Dessa forma, o manejo de plantas daninhas em uma propriedade deve ser levado em consideração a longo prazo, através de um sistema integrado de controle em sistemas de produção que envolva métodos culturais, físicos, mecânicos, químicos, além de outros. Portanto, é necessário alterar constantemente as práticas normalmente utilizadas no controle de plantas daninhas, visando evitar ou retardar o aparecimento de plantas daninhas resistentes (López-Ovejero \& Christoffoleti, 2003).

Algumas práticas para prevenir ou manejar a resistência são:

i) Manejo apropriado dos herbicidas:

- utilização de herbicidas com pouca atividade residual no solo;

- otimização da dose, da época e do número de aplicações;

- minimização da aplicação de herbicidas específicos, evitando o uso contínuo de herbicida ou daqueles com o mesmo mecanismo de ação;

- rotação de herbicidas com mecanismos de ação diferenciados, porém efetivos, sobre o mesmo espectro de plantas daninhas. Por exemplo, uma das alternativas de manejo de população resistente ao glyphosate é a aplicação seqüencial ou em rotação com graminicidas;

ii) Rotação de culturas:

- semeadura de diferentes culturas nas safras (culturas, pastagens e forrageiras);

- semeadura de diferentes culturas nas safras que permitam a utilização de herbicidas de diferentes mecanismos de ação ou não utilizam herbicidas; e

- semeadura de diferentes culturas que permitam nas safras a utilização de métodos alternativos de controle (diferentes do químico).

iii) Monitoramento após aplicação dos herbicidas:

- monitoramento das manchas de plantas daninhas com padrão diferente com problemas de aplicação; e

- eliminação de focos iniciais de resistência com azevém (evitar produção de sementes).

iv) utilização de práticas não-químicas que objetivem o fortalecimento da capacidade competitiva da cultura, representada pelo seu rápido estabelecimento e desenvolvimento. 
v) Práticas de cultivo mecânico (enxada rotativa e cultivadores seletivos).

vi) Prevenção da disseminação de sementes através do uso de equipamentos limpos.

vii) Evitar a disseminação de azevém resistente. Essa prática pode ser efetuada evitandose a utilização de sementes de azevém para plantio com forrageira originária da limpeza de sementes de cereais (beneficiadoras). Esta prática pode estar beneficiando a disseminação de sementes resistentes.

viii) Culturas de inverno com dessecação o mais cedo possível, controlando assim o azevém em estádio mais jovem de crescimento e, conseqüentemente, em estádios mais suscetíveis.

ix) Prática de ressemeadura com azevém suscetível. Esta prática cria uma competição intra-específica entre os biótipos de azevém (resistentes e suscetiveis), diluindo, assim, a freqüência do gene de resistência presente na população da área.

\section{CONSIDERAÇÕES FINAIS}

A seleção de biótipos de plantas daninhas resistentes a herbicidas no Brasil e no mundo é um fenômeno já constatado e relatado para praticamente todos os herbicidas em uso na agricultura. No entanto, a freqüência de aparecimento dos casos de resistência é variável em função do herbicida, da planta daninha e do sistema de produção. O herbicida glyphosate, apesar de seu uso intensivo na agricultura, tem poucos registros de casos quando comparado com outras classes de herbicida; no entanto, neste ano foi constatado no Brasil um caso de resistência da planta daninha azevém (Lolium multiflorum). Por essa razão, o conhecimento das características das plantas daninhas, dos herbicidas e do sistema de produção que favorecem o aparecimento de biótipos de plantas daninhas resistentes a herbicidas - é de fundamental importância para que técnicas de manejo sejam utilizadas a fim de evitar ou retardar o aparecimento de plantas resistentes em uma área; caso já esteja presente na área, deve-se evitar sua disseminação e reduzir sua presença. É necessário ressaltar que, embora a seleção de biótipos de plantas daninhas resistentes seja um fato que exija cuidados e mudanças nas práticas agrícolas, não é um fenômeno que inviabilize o uso de herbicidas; é, pois, um fenômeno que exige do produtor racionalização de medidas de manejo de plantas daninhas.

\section{LITERATURA CITADA}

ARIAS, D.; RIESEBERG, H. Gene flow between cultivated and wild sunflowers. Theor. Appl. Genetics. SpringuerVerlag, 1994. $655 \mathrm{p}$.

BAERSON, S. R. et al. Investigating the mechanism of glyphosate resistance in rigid ryegrass Lolium ridigum). Weed Sci., v. 50, p. 721-730, 2002.

BRACAMONTE, E. R.; NOVO, R. J.; RINDERSTMA, L. Impacto de la soja (Glycine max (L.) Merr.) transgénica en el perfil productivo agrícola en Argentina. In: DE PRADO, R., JORRÍN, J. V. (Eds.) Uso de herbicidas em la agricultura Del siglo XXI/[II Simposium Internacional ... Córdoba, 2001.]; - Cordoba: Servicio de Publicaciones de la Universidad de Córdoba, 2001. p. 619-625.

BRADSHAW, L. D. Perspective of glyphosate resistance. Weed Tech., v. 11, n. 1, p. 189-198, 1997.

CAPENTER, J. et al. Comparative Environmental Impacts of Biotechnology-derived and traditional soybeas, corn, and cotton crops. Council for Agricultural Science and Technology. Ames: Iowa, 2002. 190 p.

COMITÊ BRASILEIRO DE RESISTÊNCIA DE PLANTAS A HERBICIDAS - CBRPH. Resistência de plantas daninhas a herbicidas. É Melhor Prevenir do que Remediar. Londrina: SBCPD, 2000. $32 \mathrm{p}$.

CHRISTOFFOLETI, P. J. Curvas de dose-resposta de biótipos resistente e suscetível de Bidens pilosa L. aos herbicidas inibidores da ALS. Scientia Agrícola, v. 59, n. 3, p. 513-519, 2002.

CHRISTOFFOLETI, P. J.; LÓPEZ-OVEJERO, R. F. Definições e situação da resistência de plantas daninhas aos herbicidas no Brasil e no mundo. In: CHRISTOFFOLETI, P. J. (Coord.) Aspectos de resistência de plantas daninhas a herbicidas. Londrina: Associação Brasileira de Ação a resistência de Plantas aos Herbicidas (HRAC-BR), 2003. p. 2-21.

CHRISTOFFOLETI, P. J.; VICTORIA FILHO, R.; SILVA, C. B. Resistência de plantas daninhas aos herbicidas. Planta Daninha, v. 12, n. 1, p. 13-20, 1994.

FENG, P. C. C.; PRATLEY, J. E.; BOHN, J. A. Resistance to glyphosate in Lolium rigidum. II. Uptake, translocation, and metabolism. Weed Sci., v. 47, p. 412-415, 1999.

KISSMANN, K. G. Resistência de plantas a herbicidas. São Paulo: Basf Brasileira S.A., 1996. 33 p. 
KRUSE, N. D.; TREZZI, M. M.; VIDAL, R. A. Herbicidas inibidores da EPPSs: Revisão de literatura. R. Bras.Herb., v. 1; n. 2, p. 139-146, 2000.

LEE, L. J.; NGIM, J. A first report of glyphosate-resistant goosegrass (Eleusine indica (L.) Gaertn.) in Malaysia. Pest. Manag. Sci., v. 56, p. 336-339, 2000.

LÓPEZ-OVEJERO, R. F.; CHRISTOFFOLETI, P. J. Recomendações para prevenção e manejo da resistência a herbicidas. In: CHRISTOFFOLETI, P.J. (Coord.) Aspectos de resistência de plantas daninhas a herbicidas. Londrina: Associação Brasileira de Ação a resistência de Plantas aos herbicidas (HRAC-BR), 2003. p. 45-79.

MAXWELL, B. D.; MORTIMER, A. M. Selection for herbicide resistance. In: POWLES, S. B.; HOLTUR, J. A. $M$. Herbicide resistance in plants: biology and biochemistry. Boca Raton: Lewis, 1994. p. 1-26.

PRATLEY, J. et al. Glyphosate resistance in annual ryegrass. Sidney: NSW, 2000. p.122. (Proc. Eleventh Annual Conference Grassld. Sc)
PRATLEY, J. et al. Resistance to glyphosate in Lolium rigidum. I Bioevolution. Weed Sci., v. 47, p. 405-411, 1999.

PUPO, N. I. H. Manual de pastagens e forrageiras: formação, conservação, utilização. Campinas: Instituto Campineiro de Ensino Agrícola, 1979. 343 p.

TRAN, M. et al. Characterization of glyphosate resistant Eleusine indica biotypes from Malaysia. In: Proc. $17^{\text {th }}$ Asian-Pacific Weed Soc. Conf., 1999. p. 527-536.

VARGAS, L. et al. Resistência de plantas daninhas a herbicidas. Viçosa,MG: Jard, 1999. 131p.

VIDAL, R. A.; FLECK, N. G. Análise do risco da ocorrência de biótipos de plantas daninhas resistentes aos herbicidas. Planta Daninha, v. 15, n. 12, p. 152-161, 1997.

WEED SCIENCE. International survey of herbicide resistant weeds. Disponível em $<$ http://

www.weedscience.org/in.asp >. Acesso em: 12 de dezembro de 2003. 